\title{
Biosensors for Fungal Detection
}

\author{
Hamdi Nsairat* (D), Areej M. Jaber (D) and Mazen Al-Sulaibi \\ Pharmacological and Diagnostic Research Center, Faculty of Pharmacy, Al-Ahliyya Amman University, \\ Amman 19328, Jordan.
}

\begin{abstract}
Due to the serious threat of invasive fungal infections, there is an emergent need for improved a sensitive and more accurate diagnostic tests for detection of systemic pathogenic fungi and plant health. Traditional fungal diagnosis can only be achieved at later growing phases. The complex and difficult immunodiagnostic is also widely employed. Enzyme-based immunoassays which lead to cross-interaction with different fungi still also obeyed. A polymerase chain reactions (PCRs)- based molecular diagnosis are does not enable precise identification of fungal pathogens, or the ability to test isolates for drug sensitivity. In the future, biosensing technologies and nanotechnological tools, will improve diagnosis of pathogenic fungi through a specific and sensitive pathogen detection. This report systematically reviews the most prominent biosensor trends for fungi detection.
\end{abstract}

Keywords: Fungi, Biosensors, Luminescence, Fluoresence

(C) The Author(s) 2021. Open Access. This article is distributed under the terms of the Creative Commons Attribution 4.0 International License which permits unrestricted use, sharing, distribution, and reproduction in any medium, provided you give appropriate credit to the original author(s) and the source, provide a link to the Creative Commons license, and indicate if changes were made. 


\section{INTRODUCTION}

Fungal Kingdom almost involves one million classes and only 400 of them cause disease and being harmful to humans. ${ }^{1}$ Yeast fungi, as Candida albicans, usually related to commensal symbiont in human hosts and considered extremely opportunistic pathogen. ${ }^{2,3}$

Clinical measurements showed that the aggressive fungal infections have rapidly been growing for last years. Despite new antifungal therapeutic approaches, increased mortality rates caused by fungal diseases remains a serious challenge. ${ }^{4,5}$ Under such circumstances, there is an increasing demand for the early, reliable, and fast detection of these infections at their initial phase of development, which is essential for effective treatments as well as the reduction of deaths and medical costs. ${ }^{6}$

Biosensor technology provide suitable methodologies for fungal detection in medical and plant pathology. Biosensor is a bio-analytical tool that combines the bio-recognition unit with a signal transducer to translate the response of analytes into a quantifiable signal that is directly related to the analytes amounts [Fig. 1]. ${ }^{7}$

Biosensors represent a promising instrument to supplement advanced techniques, due to their exceptional features, such as increased selectivity, cheap, ability of automation and the possibility of data acquisition in short time.$^{8}$ In biosensors, the bio-recognition incident occurs on the fixed platform transducer surface, contrasting traditional bioanalysis procedures.

At the same level, nanotechnology provide various new analytical protocols, assemblies, and nanostructures for bio-detection, as a result of the nano-size and abnormal physico-chemical features of nanoparticles. Nanotechnology applications to biosensor have been progressively utilized to yield an enhanced pioneering tools for envisaging disease detection and diagnosis. ${ }^{9}$

\section{DISCUSSION}

Fungi biosensors could be classified into five main categories: optical, electrochemical, mass-sensitive, nanomaterials-based, and lab on-chip biosensors. Their working principles, advantages, and disadvantages are reviewed here.

\section{Fungi Optical Biosensors (OBs)}

The transduction route in OBs prompts phase change, intensity alteration, polarization shift, or incidence of the received light in response to specific transformation as a result of bio-sensing unit. OBs have the advantages of enhanced sensitivity, specificity, labeling-free bio-detection, real and short time analysis, ${ }^{10}$ active sensing, and compact structure. ${ }^{11}$ Optical biosensors can be generally categorized into:

Fluorescence Resonance Energy Biosensors (FREBs)

FREBs have been used in several medical applications for multiple analytes label-free biodetection accompanied with high sensitivity. ${ }^{12}$ This approach utilizes the arrangement of a fluorescent bio-receptor attached with an optical transducer that based on non-radioactive energy traveled from an excited donor fluorophore to a adjacent acceptor molecule. ${ }^{13}$ Fluorescent biosensors (FBs) are designed by fixing entire cells on the biosensor film. This film is generally located in the tip of optical filaments to create a fluorescent indication. ${ }^{11}$ A fluorometric biosensor used to detect and quantify aflatoxins was established by Carlson et al. ${ }^{14} \mathrm{~A}$ total of 228 specimens of oral candidiasis were exposed to fluorescent stain, and were detected by blue fluorescence surrounding their tubular or annular structures. This approach provide a rapid method for Candida detection. ${ }^{15}$ Moreover, green fluorescent proteins were utilized for many fungal detection in plants as Phytophthora palmivora, ${ }^{16}$ Colletotrichum lindemuthianum ${ }^{17}$ and Aspergillus nidulans ${ }^{18}$ for plant pathogens.

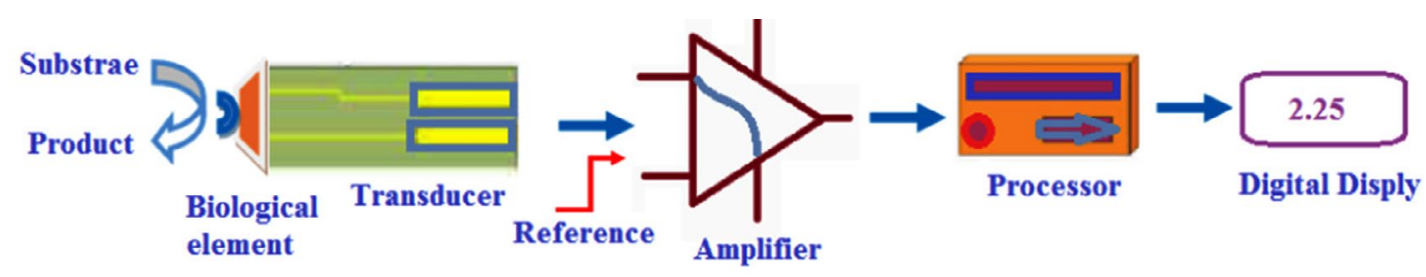

Fig. 1. Schematic representation of a biosensor (Adapted from Ref [ $\left.{ }^{69}\right]$ ). 
Kakoschke and colleagues described an immunofluorescence analysis that can detect a fungus from a colony in approximately $60 \mathrm{~min}$. Where the materials from colonies are bound to adhesive tape and stained with appropriate antibodies; allowing analysis by confocal laser scanning microscopy. ${ }^{19}$

\section{Chemiluminescence (CL) Based Sensors}

$\mathrm{CL}$ based-sensors is a developing tool for detection and diagnostics fungal species by emission of light based on chemical reaction, ${ }^{20}$ with high sensitivity, rapid dynamic response properties, broad calibration range and low cost devices. ${ }^{11}$ DNA-based chemiluminescent optical fiber biosensor for Brettanomyces bruxellensis diagnosis was designed by Cecchini et al. This DNAbased biosensor was reproducible and fast with respect to conventional methods. ${ }^{21}$ Zangheri et al developed a CL-based smartphone for biosensing ochratoxin $A$ in wine and coffee using side flow immunoassay (LFIA)-based strategies, ${ }^{22}$ Yamashoji et al. established a menadione-catalyzed luminol $\mathrm{CL}$ biosensor for Saccharomyces cerevisiae, Yarrowia lipolytica, and Hansenula anomala detection with high sensitivity. ${ }^{23}$

Surface Plasmon Resonance Based-biosensors (SPRBs)

SPRBs were described by many scientists for fungal pathogens detection. SPRBs composed of bio-recognition agents immobilized on the surface of a thin film of gold metal placed on a glass prism interface [Fig. 2] ${ }^{10,24,25}$. An SPRBs based-immunosensor was developed by Mendes et al. Anti-Phakopsora pachyrhizi was fixed on a self-assembled monolayer gold (Au) plate. This technique offered an early, fast and linear detection for the antigen ( 3.50 to $28.00 \mathrm{ppm}$ ) to sense Asian rust (a disease that occurs in soy cultures) in the leaf extract of soybean. The effects of the antibody amount and the surface blocking to minimize non-specific adsorption on immunosensor response were evaluated. ${ }^{26}$ Moreover, Urediniospores of Puccinia striiformis f. sp. tritici (Pst) was detected using SPR basedbiosensor. This work represented the first procedure of SPR based-biosensor approach for fungal spore detection. ${ }^{27}$

Bioluminescence-Based Fungal Bioassay (BLBs) This strategy based on the bioluminescent features of Mycena citricolor and Armillaria mellea fungus, that enable a bioluminescence-based toxicity bioassay. The naturally occurring fungual luminescence varies in response to certain analytes 28BLBs provides high sensitivity, heat stable, and fast response bioassay. ${ }^{29}$ The toxicity of some chlorophenols compound derivatives, $\mathrm{Cu}$, and $\mathrm{Zn}$ were evaluated using a novel BLBs. Light decline was detected in response to the tested chlorophenols for both Armillaria mellea and Mycena citricolor. Armillaria mellea showed low sensitivity to di and penta chlorophenols than Mycena citricolor. ${ }^{30}$

However, optical biosensors still complicated, expensive, and less able for

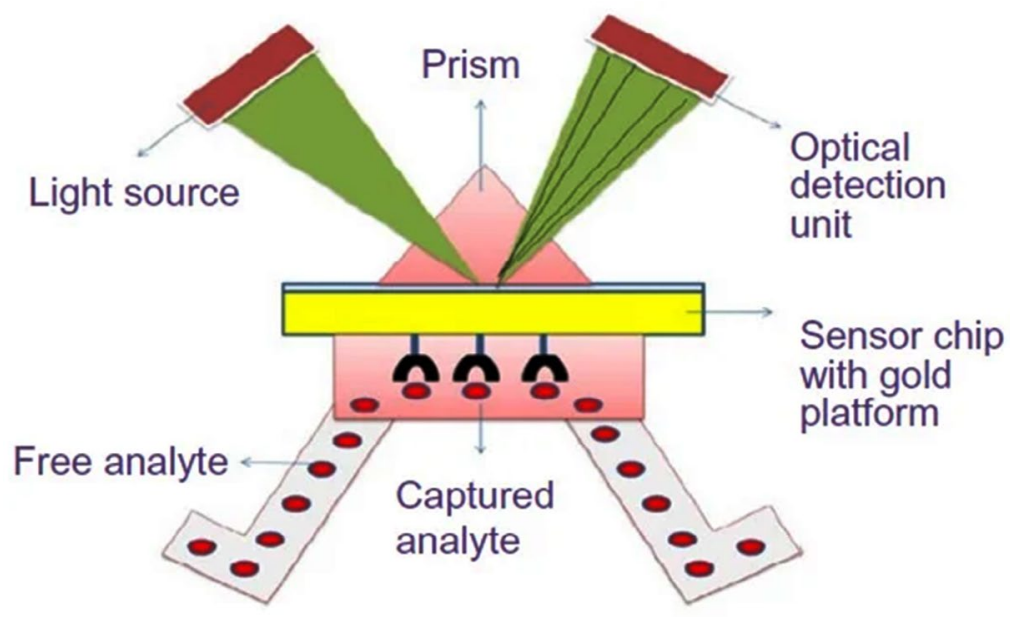

Fig. 2. Schematic representation of a SPR-based biosensor (Adapted from Ref [ $\left.{ }^{25}\right]$ ). 
miniaturization. But still optical signals have a safe ability to convey massive data in short time, making them capable for crucial in vivo bio-detection, specifically by using of fiber optic nanotechnology. ${ }^{31}$

\section{Fungi Electrochemical Biosensors}

Electrochemical biosensors (EBs) consist of an electrochemical transducer combined with a bio-receptor, that convert a reacting molecule into a measured electrical signal. ${ }^{32}$ EBs are promising transduction that has been used for fungal pathogens detection for their simple use, low economical cost, easier to be miniaturized and mass fabricated. ${ }^{11,33}$ They are classified into the following:

\section{Amperometric Biosensors (ABs)}

$A B s$ are based on a catalytic enzyme structure that translate electrochemically inactive substrate into electro-active products produce a current signal which ends to a measurable signal. Laccase from Cerrena unicolor fungus was fixed on the surface of graphite electrode and used for designing an amperometric biosensors for flavonoids bio-detection. ${ }^{34}$ Carbon paste electrodes were also functionalized with Saccharomyces cerevisiae and explored as ABs by Garjonyte et al. ${ }^{35} \mathrm{ABs}$ considered highly sensitive, low cost, and the ability to scale production, but always need regeneration between measurements. ${ }^{10,36}$

\section{Potentiometric Biosensors (PBs)}

PBs involve translation of a biorecognition into a potential signal that is sensed by a reference and stable electrode. These biosensors involved a permselective membranes or sensitive surfaces to an enzymatic bioactive molecule. The enzyme-catalyzed reaction involves production or consumption of certain substance, which is then distinguished by an ion-selective electrode. ${ }^{37} \mathrm{~A}$ PB for the permethrin detection in treated wood was designed by Mat Arip et al. The biosensor was arranged by halt of the Lentinus sajor-caju fungus cells in alginate matrix placed on a $\mathrm{pH}$-sensitive transducer. ${ }^{38} \mathrm{PBs}$ are easy to operate, indorsing quick and repeatable detection, with low-cost instrumentation, miniaturization, and mobile advance. ${ }^{39}$ In the other hand, low sensitivity is the main disadvantage for this biosensor. ${ }^{40}$

\section{Impedimetric Transduction Technique}

Electrochemical impedance spectroscopy (EIS) is relatively fast, simple and cheap noninvasive technique. ${ }^{41}$ EIS examined the binding reactions at the electrode surface. EIS based sensor to detect Candida albicans yeast was recently developed. The yeast cells were bound to an electrode modified with anti-Candida antibodies. $^{42}$

A self-accumulated monolayer/goldbased EIS for alkanethiolate detection was investigated. This biosensor was used for quantification of Saccharomyces cerevisiae fixed onto an electrode. ${ }^{43}$ EIS biosensor was also utilized for the detection of toxic Penicillium sclerotigenum in infected yams. ${ }^{44}$ EIS suffer from localized corrosion and need several surface modifications to recover this corrosion. ${ }^{45,46}$

\section{Conductometric Biosensor (CBs)}

CBs include double metal separated electrodes with a voltage applied through them to produces a current. A conductimetric analysis was utilized to detect fungal growth in the Potato Dextrose Agar medium. ${ }^{47}$ Dickert et al, developed a biosensor using living fungal cells as models for

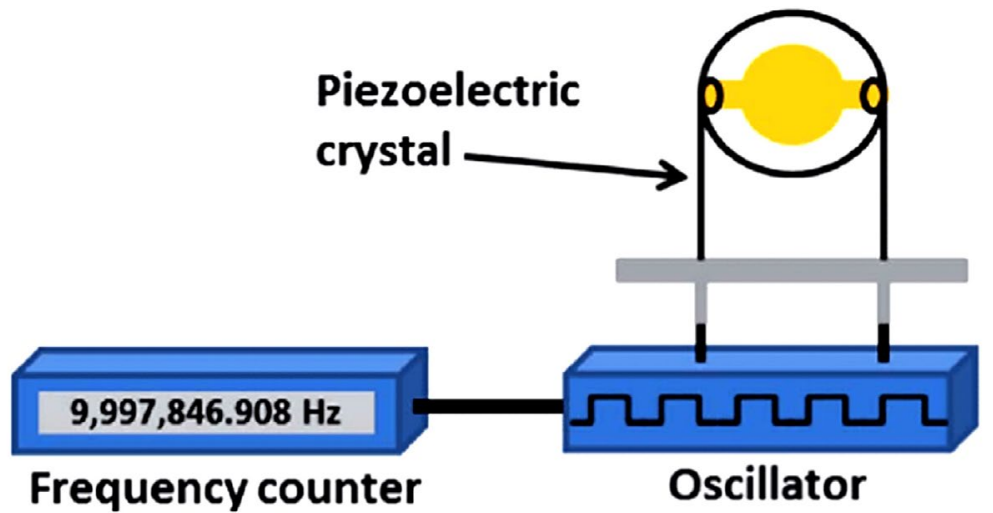

Fig. 3. A piezoelectric quartz crystal based biosensor (Adapted from Ref [51]) 
molecularly imprinted polymers. It based on the quartz crystal microbalance principle for entire cell sensing and on the sedimentation properties of the yeasts. ${ }^{48} \mathrm{~A}$ bio-detection is based on a fieldeffect transistor with the single-walled carbon nanotubes (SWCNTs) network as the conducting tubes was developed. The monoclonal antibodies against Candida albicans were immobilized onto SWCNTs, to provide precise binding sites for fungal antigens. $^{49}$

Electrochemical biosensors usually exhibit lower sensitivity, ${ }^{50}$ and their tendency for interferences produced by electrochemically active substances delaying effects across sensing electrodes. $^{31}$

\section{Mass-Sensitive Biosensors (MSBs)}

Sensitive mass analysis is based on the use of piezoelectric quartz crystals [Fig. 3]. ${ }^{11,51}$ The crystals are vibrate under electrical signal of a certain frequency. ${ }^{52}$ The frequency of oscillation depends on the applied electrical field and the crystal mass. Therefore, the change in the frequency of oscillation crystal can be measured electrically..$^{53}$ Mass based detection offers realtime operation and fungal monitoring in different environments, ${ }^{54}$ quite easy to use, low cost, a label-free analysis with increased sensitivity and specificity. ${ }^{11,53}$ Nugaeva et al, reported a MSBs to sense Aspergillus niger and Saccharomces cerevisiae growth phase. Cantilever sensors are a class of piezoelectric crystals used for short-time detection of Aspergillus niger and Saccharomyces cereviiae. ${ }^{55}$

\section{Nanomaterials-Based Biosensors (NBB)}

Nanoparticles (NPs) showed an enhanced electronic and optical properties compared to bulk forms. NPs can improve target analyte binding by possess a high surface area (SA), ${ }^{56}$ sensitivity and low limit of detection of biosensors by increasing SA onto which bio-element can be fixed. ${ }^{11,57}$ Gold nanoparticles (AuNPs) are the most frequently used NPs in biosensors, because of high electro-activity and electronic conductivity. ${ }^{58} \mathrm{~A}$ sensitiveEBs, using modified Au electrode with Cu-NPs was settled to measure salicylic acid in oil seeds to sense the Sclerotinia sclerotiorum. ${ }^{59}$ Allergenic fungal spores of Aspergillus niger were detected colorimetry based on AuNPs modified with a particular peptide. This platform produced visible color change of the supernatant after spores sedimentation. This biosensorshowed an enhanced spores sensitivity with less than 10 min detection time. ${ }^{60} \mathrm{TiO}_{2}$ or $\mathrm{SnO}_{2} \mathrm{NPs}$ of on carbon electrodes have been established for p-ethylguaiacol sensing, a fingerprint material evolved from pathogenic fungus Phytophthora cactorum. ${ }^{61}$

\section{Lab on Chip (LOC) devices}

Microfluidic LOC strategies improve fungi detection and diagnosis in blood samples. ${ }^{62}$ These biosensors enable resource-constrained settings when no central laboratories available for implementing culturing procedures. ${ }^{2}$ Cai et al designed a microfluidic LOC based on Slip ChipVR to distinguish various fungi in blood samples simultaneously. ${ }^{63}$ A modern liquid logic chip for Candida albicans detection in blood samples were developed by Schell et al. The DNA extraction was employed off-chip and the purified DNA was functional to the bio-chip. ${ }^{64}$ Alternative approach is depend on Raman spectroscopy to detect a distinct vibration spectrum of various structures of fungus on Sabouraud medium or blood culture. ${ }^{65}$ Recently, Asghar et al developed an immuno-based microfluidic chip for fast detection of Candida albicans in blood with an efficiency of $61-78 \% .{ }^{66}$

Recently, a real time PCR approach for Candida albicans detection in human blood was developed. Quantitative PCR (qPCR) assays represented a noticeable detection limit of 0.2 $\mathrm{CFU} / \mu \mathrm{L}$. The assay efficiency ranged from 89.67 to $97.07 \% .{ }^{67}$ Yu et al., utilized LOC diagnostic system for fast detection of azole-resistant Aspergillus fumigatus in different samples. ${ }^{68}$

\section{CONCLUSION AND FINAL REMARKS}

Current culture-based methodologies to detect and identify fungal pathogens are too slow with low success rates due to the decreased sensitivity of blood culture structures to detect these slow growing microorganisms. Challenges and complications will maintain developing a commercially rapid assays for fungal disease detection. Some of these challenges are the solid scientific information deficiencies and the progress of standardized fast tests, particularly when massproduction and high-throughput detection are expected.

In this mini-review we have summarized a different trend for a rapid biosensing of various 
fungal pathogens. Thus, with the improvements in biosensor technology, it is possible to analyze a number of biomarkers in field determinations. Considering the dangers associated to fungal infection, the design and applications of imprinted biosensors for quick detection in many different types of situations, will find effective applications. We expect the improvement of enhanced sample processing boards attached to improved sensitive detection systems, possibly in the form of lab-ona-chip and/or microfluidic devices, for low cost and smart laboratorial and in-the-field fungal detection.

\section{ACKNOWLEDGMENTS}

None.

\section{CONFLICT OF INTEREST}

The authors declare that there is no conflict of interest.

\section{AUTHORS' CONTRIBUTION}

All authors have made a substantial, direct and intellectual contribution to the work, and approved it for publication.

\section{FUNDING}

None.

\section{DATA AVAILABILITY}

All datasets generated or analyzed during this study are included in the manuscript.

\section{ETHICS STATEMENT}

This article does not contain any studies with human participants or animals performed by any of the authors.

\section{REFERENCES}

1. Fridkin SK, Jarvis WR. Epidemiology of nosocomial fungal infections. Clin Microbiol Revi. 1996;9(4):499511. doi: 10.1128/CMR.9.4.499-511.1996

2. Safavieh $\mathrm{M}$, Coarsey $\mathrm{C}$, Esiobu $\mathrm{N}$, et al. Advances in Candida detection platforms for clinical and point-ofcare applications. Crit Rev Biotechnol. 2017;37(4):441458. doi: 10.3109/07388551.2016.1167667

3. Borman AM, Fraser M, Johnson EM. CHROMagar ${ }^{\mathrm{TM}}$ Candida Plus: A novel chromogenic agar that permits the rapid identification of Candida auris. Medical Mycology. 2021;59(3):253-258. doi: 10.1093/mmy/ myaa049

4. Alcazar-Fuoli L, Mellado E. Current status of antifungal resistance and its impact on clinical practice. British Journal of Haematology. 2014;166(4):471-484. doi: 10.1111/bjh.12896

5. Pfaller MA, Wolk DM, Lowery TJ. T2MR and T2Candida: novel technology for the rapid diagnosis of candidemia and invasive candidiasis. Future Microbiology. 2015;11(1):103-117. doi: 10.2217/fmb.15.111

6. Guery BP, Arendrup MC, Auzinger G, et al. Management of invasive candidiasis and candidemia in adult nonneutropenic intensive care unit patients: Part II. Treatment. Intensive Care Medicine. 2009;35(2):206214. doi: $10.1007 / \mathrm{s} 00134-008-1339-6$

7. Lei Y, Chen W, Mulchandani A. Microbial biosensors. Analytica Chimica Acta. 2006;568(1-2):200-210. doi: 10.1016/j.aca.2005.11.065

8. Roda A, Mirasoli M, Michelini E, et al. Progress in chemical luminescence-based biosensors: A critical review. Biosens Bioelectron. 2016;76:164-179. doi: 10.1016/j.bios.2015.06.017

9. Teles FR, Martins ML. Laboratorial diagnosis of paracoccidioidomycosis and new insights for the future of fungal diagnosis. Talanta. 2011;85(5):2254-2264. doi: 10.1016/j.talanta.2011.07.099

10. Oliveira IS, da Silva Junior AG, de Andrade CAS, Oliveira MDL. Biosensors for early detection of fungi spoilage and toxigenic and mycotoxins in food. Current Opinion in Food Science. 2019;29:64-79. doi: 10.1016/j. cofs.2019.08.004

11. Ray M, Ray A, Dash S, et al. Fungal disease detection in plants: Traditional assays, novel diagnostic techniques and biosensors. Biosensors and Bioelectronics. 2017;87:708-723. doi: 10.1016/j.bios.2016.09.032

12. He B, Yan X. A "signal-on" voltammetric aptasensor fabricated by hcPt@AuNFs/PEI-rGO and $\mathrm{Fe}_{3} \mathrm{O}_{4} \mathrm{NRs} /$ $\mathrm{rGO}$ for the detection of zearalenone. Sensors and Actuators B: Chemical. 2019;290:477-483. doi: 10.1016/j.snb.2019.04.005

13. Shi J, Tian F, Lyu J, Yang M. Nanoparticle based fluorescence resonance energy transfer (FRET) for biosensing applications. J Mater Chem $B$. 2015;3(35):6989-7005. doi: 10.1039/C5TB00885A

14. Carlson MA, Bargeron CB, Benson RC, et al. An automated, handheld biosensor for aflatoxin. Biosens Bioelectron. 2000;14(10-11):841-848.

15. Yao Y, Shi L, Zhang C, Sun H, Wu L. Application of fungal fluorescent staining in oral candidiasis: diagnostic analysis of 228 specimens. BMC Microbiology. 2019;19(1):96. doi: 10.1186/s12866-019-1467-x

16. Riedel M, Calmin G, Belbahri L, et al. Green fluorescent protein (GFP) as a reporter gene for the plant pathogenic oomycete Phytophthora ramorum. J Eukaryot Microbiol. 2009;56(2):130-135. doi: 10.1111/j.1550-7408.2008.00376.x

17. Dumas B, Centis S, Sarrazin N, Esquerre-Tugaye MT. Use of green fluorescent protein to detect expression of an endopolygalacturonase gene of Colletotrichum lindemuthianum during bean infection. Appl Environ Microbiol. 1999;65(4):1769-1771. doi: 10.1128/ AEM.65.4.1769-1771.1999

18. Fernandez-Abalos JM, Fox H, Pitt C, Wells B, Doonan JH. Plant-adapted green fluorescent protein is a versatile vital reporter for gene expression, protein localization 
and mitosis in the filamentous fungus, Aspergillus nidulans. Molecular Microbiology. 1998;27(1):121130. doi: 10.1046/j.1365-2958.1998.00664.x

19. Kakoschke TK, Kleinemeier C, Langenmayer MC, Ebel F. Tape mount immunostaining: a versatile method for immunofluorescence analysis of fungi. Future Microbiology. 2019;14(4):275-282. doi: 10.2217/fmb2018-0283

20. Wang $Y$, Liu Z, Wang $X$, et al. Rapid and quantitative analysis of exosomes by a chemiluminescence immunoassay using superparamagnetic iron oxide particles. J Biomed Nanotechnol. 2019;15(8):17921800. doi: 10.1166/jbn.2019.2809

21. Cecchini F, Manzano M, Mandabi Y, Perelman E, Marks RS. Chemiluminescent DNA optical fibre sensor for Brettanomyces bruxellensis detection. J Biotechnol. 2012;157(1):25-30. doi: 10.1016/j.jbiotec.2011.10.004

22. Zangheri M, Di Nardo F, Calabria D, et al. Smartphone biosensor for point-of-need chemiluminescence detection of ochratoxin A in wine and coffee. Analytica Chimica Acta. 2021;1163:338515. doi: 10.1016/j. aca.2021.338515

23. Yamashoji S, Asakawa A, Kawasaki S, Kawamoto S. Chemiluminescent assay for detection of viable microorganisms. Anal Biochem. 2004;333(2):303-308. doi: 10.1016/j.ab.2004.05.043

24. Damborsky P, Svitel J, Katrlik J. Optical biosensors. Essays in Biochemistry. 2016;60(1):91-100. doi: 10.1042/EBC20150010

25. Kumar H, Rani N. Enzyme-based electrochemical biosensors for food safety: a review. Nanobiosensors in Disease Diagnosis. 2016;5:29-39. doi: 10.2147/NDD. S64847

26. Mendes RK, Carvalhal RF, Stach-Machado DR, Kubota LT. Surface plasmon resonance immunosensor for early diagnosis of Asian rust on soybean leaves. Biosens Bioelectron. 2009;24(8):2483-2487. doi: 10.1016/j. bios.2008.12.033

27. Skottrup $\mathrm{P}$, Hearty S, Frokiaer $\mathrm{H}$, et al. Detection of fungal spores using a generic surface plasmon resonance immunoassay. Biosens Bioelectron. 2007;22(11):27242729. doi: 10.1016/j.bios.2006.11.017

28. Saini R, Hegde K, Brar SK, Verma M. Chapter 13 - Advances in whole cell-based biosensors in environmental monitoring. Tools, Techniques and Protocols for Monitoring Environmental Contaminants. 2019:263-284. doi: 10.1016/B978-0-12-8146798.00013-3

29. Borisov SM, Wolfbeis OS. Optical Biosensors. Chemical Reviews. 2008;108(2):423-461. doi: 10.1021/ cr068105t

30. Weitz HJ, Campbell CD, Killham K. Development of a novel, bioluminescence-based, fungal bioassay for toxicity testing. Environ Microbiol. 2002;4(7):422-429. doi: 10.1046/j.1462-2920.2002.00315.x

31. Teles FSRR, de Tavora Tavira LAP, da Fonseca LJP. Biosensors as rapid diagnostic tests for tropical diseases. Critical Reviews in Clinical Laboratory Sciences. 2010;47(3):139-169. doi: 10.3109/10408363.2010.518405
32. Vargas-Bernal, R.; Rodríguez-Miranda, E.; HerreraPérez, G. Evolution and Expectations of Enzymatic Biosensors for Pesticides. Intech. 2012; Chapter: 14, first edition. doi: 10.5772/46227.

33. Cui F, Zhou Z, Zhou HS. Molecularly imprinted polymers and surface imprinted polymers based electrochemical biosensor for infectious diseases. Sensors. 2020;20(4):996. doi: 10.3390/s20040996

34. Jarosz-Wilkolazka A, Ruzgas T, Gorton L. Use of laccasemodified electrode for amperometric detection of plant flavonoids. Enzyme Microbial Technol. 2004;35(23):238-241. doi: 10.1016/j.enzmictec.2004.04.016

35. Garjonyte R, Melvydas V, Malinauskas A. Mediated amperometric biosensors for lactic acid based on carbon paste electrodes modified with baker's yeast Saccharomyces cerevisiae. Bioelectrochemistry. 2006;68(2):191-196. doi: 10.1016/j.bioelechem.2005.08.002

36. Sys M, Oblukova M, Kolivoska V, Sokolova R, Korecka L, Mikysek T. Catalytic properties of variously immobilized mushroom tyrosinase: A kinetic study for future development of biomimetic amperometric biosensors. Journal of Electroanalytical Chemistry. 2020;864:114066. doi: 10.1016/j. jelechem.2020.114066

37. Damiati S, Schuster B. Electrochemical Biosensors Based on S-Layer Proteins. Sensors. 2020;20(6):1721. doi: 10.3390/s20061721

38. Arip MN, Heng LY, Ahmad M, Ujang S. A cell-based potentiometric biosensor using the fungus Lentinus sajor-caju for permethrin determination in treated wood. Talanta. 2013;116:776-781. doi: 10.1016/j. talanta.2013.07.065

39. Ding J, Qin W. Recent advances in potentiometric biosensors. TrAC Trends in Analytical Chemistry. 2020;124:115803. doi: 10.1016/j.trac.2019.115803

40. Deng $\mathrm{K}$, Zhang $\mathrm{Y}$, Tong X-D. A novel potentiometric immunoassay for carcinoma antigen $15-3$ by coupling enzymatic biocatalytic precipitation with a nanogold labelling strategy. Analyst. 2018;143(6):1454-1461. doi: 10.1039/C7AN02091K

41. Alejnikov AF, Cheshkova AF, Mineev VV. Choice of impedance parameter of strawberry tissue for detection of fungal diseases. IOP Conference Series: Earth and Environmental Science. 2020;548:032005. doi: 10.1088/1755-1315/548/3/032005

42. Kwasny D, Tehrani SE, Almeida C, Schjodt I, Dimaki M, Svendsen WE. Direct Detection of Candida albicans with a Membrane Based Electrochemical Impedance Spectroscopy Sensor. Sensors. 2018;18(7):2214. doi: $10.3390 / \mathrm{s} 18072214$

43. Chen H, Heng CK, Puiu PD, et al. Detection of Saccharomyces cerevisiae immobilized on selfassembled monolayer (SAM) of alkanethiolate using electrochemical impedance spectroscopy. Analytica Chimica Acta. 2005;554(1-2):52-59. doi: 10.1016/j. aca.2005.08.086

44. Silva GJL, Andrade CAS, Oliveira IS, de Melo CP, Oliveira MDL. Impedimetric sensor for toxigenic Penicillium sclerotigenum detection in yam based on magnetite- 
poly(allylamine hydrochloride) composite. J Colloid Interface Sci. 2013;396:258-263. doi: 10.1016/j. jcis.2013.01.023

45. Hamdy AS, El-Shenawy E, El-Bitar T. Electrochemical impedance spectroscopy study of the corrosion behavior of some niobium bearing stainless steels in $3.5 \% \mathrm{NaCl}$. International Journal of Electrochemical Science. 2006;1(4):171-180.

46. Balusamy T, Narayanan TSNS, Ravichandran K, Park IS, Lee MH. Influence of surface mechanical attrition treatment (SMAT) on the corrosion behaviour of AISI 304 stainless steel. Corrosion Science. 2013;74:332344. doi: 10.1016/j.corsci.2013.04.056

47. Sawai J, Yoshikawa T. Measurement of fungi by an indirect conductimetric assay. Lett Appl Microbiol. 2003;37(1):40-44. doi: 10.1046/j.1472765X.2003.01344.x

48. Dickert FL, Hayden G. Bioimprinting of polymers and sol-gel phases. Selective detection of yeasts with imprinted polymers. Anal Chem. 2002;74(6):13021306. doi: 10.1021/ac010642k

49. Villamizar RA, Maroto A, Rius FX. Improved detection of Candida albicans with carbon nanotube fieldeffect transistors. Sensors and Actuators B: Chemical. 2009;136(2):451-457. doi: 10.1016/j.snb.2008.10.013

50. Pohanka M, Jun D, Kuca K. Mycotoxin assays using biosensor technology: A review. Drug and Chemical Toxicology 2007;30(3):253-261. doi: 10.1080/01480540701375232

51. Srivastava SK, Rijn CJM, Jongsma MA. Biosensor-based detection of Tuberculosis. RSC Adv. 2016;6(22):17759-17771. doi: $10.1039 /$ C5RA15269K

52. Alhadrami HA. Biosensors: Classifications, medical applications, and future prospective. Biotechnol Appl Biochem. 2018;65(3):497-508. doi: 10.1002/bab.1621

53. Velusamy V, Arshak K, Korostynska O, Oliwa K, Adley C. An overview of foodborne pathogen detection: in the perspective of biosensors. Biotechnol Adv. 2010;28(2):232-254. doi: 10.1016/j. biotechadv.2009.12.004

54. Raiteri R, Grattarola M, Butt H-J, Skladal P. Micromechanical cantilever-based biosensors. Sensors and Actuators B: Chemical. 2001;79(2-3):115-126. doi: 10.1016/S0925-4005(01)00856-5

55. Nugaeva N, Gfeller KY, Backmann N, Lang HP, Duggelin M, Hegner M. Micromechanical cantilever array sensors for selective fungal immobilization and fast growth detection. Biosens Bioelectron. 2005;21(6):849-856. doi: 10.1016/j.bios.2005.02.004

56. Sutarlie L, Ow SY, Su X. Nanomaterials-based biosensors for detection of microorganisms and microbial toxins. Biotechnol J. 2017;12(4). doi: 10.1002/biot.201500459

57. Nayl AA, Abd-Elhamid Al, El-Moghazy AY, et al. The nanomaterials and recent progress in biosensing systems: A review. Trends in Environmental Analytical
Chemistry. 2020;26:e00087. doi: 10.1016/j.teac.2020. e00087

58. Cao X, Ye Y, Liu S. Gold nanoparticle-based signal amplification for biosensing. Anal Biochem. 2011;417(1):1-16. doi: 10.1016/j.ab.2011.05.027

59. Wang Z, Wei F, Liu S-Y, et al. Electrocatalytic oxidation of phytohormone salicylic acid at copper nanoparticlesmodified gold electrode and its detection in oilseed rape infected with fungal pathogen Sclerotinia sclerotiorum. Talanta. 2010;80(3):1277-1281. doi: 10.1016/j.talanta.2009.09.023

60. Lee Jl, Jang SC, Chung J, et al. Colorimetric allergenic fungal spore detection using peptide-modified gold nanoparticles. Sensors and Actuators B: Chemical. 2021;327:128894. doi: 10.1016/j.snb.2020.128894

61. Fang $Y$, Umasankar $Y$, Ramasamy RP. Electrochemical detection of $p$-ethylguaiacol, a fungi infected fruit volatile using metal oxide nanoparticles. Analyst. 2014;139(15):3804-3810. doi: 10.1039/C4AN00384E

62. Posch W, Heimdorfer D, Wilflingseder D, LassFlorl C. Invasive candidiasis: future directions in non-culture based diagnosis. Expert Review of Anti-infective Therapy. 2017;15(9):829-838. doi: 10.1080/14787210.2017.1370373

63. Cai D, Xiao M, Xu P, Xu YC, Du W. An integrated microfluidic device utilizing dielectrophoresis and multiplex array PCR for point-of-care detection of pathogens. Lab on a Chip. 2014;14(20):3917-3924. doi: 10.1039/C4LC00669K

64. Schell WA, Benton JL, Smith PB, et al. Evaluation of a digital microfluidic real-time PCR platform to detect DNA of Candida albicans in blood. Eur J Clin Microbiol Infect Dis. 2012;31(9):2237-2245. doi: 10.1007/ s10096-012-1561-6

65. Cheng I-F, Chang H-C, Hou D, Chang HC. An integrated dielectrophoretic chip for continuous bioparticle filtering, focusing, sorting, trapping, and detecting. Biomicrofluidics. 2007;1(2):21503. doi: 10.1063/1.2723669

66. Asghar W, Sher M, Khan NS, Vyas JM, Demirci U. Microfluidic Chip for Detection of Fungal Infections. ACS Omega. 2019;4(4):7474-7481. doi: 10.1021/ acsomega.9b00499

67. Busser FD, Coelho VC, Fonseca CA, et al. A Real Time PCR strategy for the detection and quantification of Candida albicans in human blood. Revista do Instituto de Medicina Tropical de Sao Paulo. 2020;62:e9. doi: 10.1590/s1678-9946202062009

68. Yu L-S, Rodriguez-Manzano J, Moser N, et al. Rapid Detection of Azole-Resistant Aspergillus fumigatus in Clinical and Environmental Isolates by Use of a Lab-on-a-Chip Diagnostic System. J Clin Microbiol. 2020;58(11): e00843-20. doi: 10.1128/JCM.00843-20

69. Hussain KK, Malavia D, Johnson EM, et al. Biosensors and Diagnostics for Fungal Detection. Journal of Fungi. 2020;6(4):349. doi: 10.3390/jof6040349 